\title{
Depicting Intralinguistic and Extralinguistic Contexts to Generate Communicative Skills to Foreign Speakers of the Indonesian Language
}

\author{
R. Kunjana Rahardi ${ }^{1}$, Yuliana Setyaningsih ${ }^{2}$, Rishe Purnama Dewi ${ }^{3}$, Danang Satria \\ Nugraha $^{4}$ \\ ${ }^{1,2}$ Master Program of Indonesian Language Education, Faculty of Teachers' Training and \\ Education, Sanata Dharma University, Yogyakarta, Indonesia \\ ${ }^{3,4}$ Undergraduate Program of Indonesian Language and Literature Education, Faculty of \\ Teachers' Training and Education, Sanata Dharma University, Yogyakarta, Indonesia \\ 1kunjana@usd.ac.id, kunjana.rahardi@gmail.com
}

\begin{abstract}
It is not sufficient for BIPA learners to understand basic linguistic elements such as grammatical structures, vocabulary, and pronunciation to achieve optimum communicative competence in the Indonesian language. Optimum communicative competence must also cover understanding of intralinguistic and extralinguistic contexts embedded in a language entity. For this purpose, it is urgent to describe two types of contexts which must be understood by BIPA learners. This research aims to describe the intralinguistic and extralinguistic contexts necessary to consider and understand the speaker's meaning, especially for foreign speakers learning the Indonesian language. Data are gathered from various sources and experts of authority. Since the researcher is the native Indonesian speaker, the data are also drawn from his linguistic intuition. The data gathering methods are the observation and conversation methods, each employing the basic and advanced techniques. The collected data are then classified and typified to obtain types of data to be subjects of proper analysis method and technique. The analysis method in this research is content analysis. The research results show that there are several intralinguistic contexts in the Indonesian language that must be considered by BIPA learners to achieve optimum communicative competence.
\end{abstract}

Keywords: Intralinguistic contexts, Extralinguistic contexts, BIPA learning

\section{PENDAHULUAN}

Bahasa Indonesia di era revolusi industri 4.0 ini semakin mendapatkan tempat di hati warga negara asing yang memang tertarik dengan Indonesia. Ketertarikan mereka itu dipicu, bukan saja karena Indonesia semakin maju sehingga menarik perhatian mereka untuk berkunjung ke negeri ini [1], [2]. Akan tetapi juga karena dimensi-dimensi sosial dan budaya Indonesia yang berkembang sangat signifikan pada akhir-akhir ini sungguh telah berhasil memikat perhatian mereka untuk belajar bahasa Indonesia. Mereka sadar, bahwa menggeluti budaya Indonesia tidak dapat dipisahkan dengan menggeluti bahasa Indonesia karena pada hakikatnya keduanya adalah sekeping uang logam bersisi dua [3], [4]. 
Keputusan mereka untuk menggeluti budaya dan bahasa Indonesia tentu tidak dapat dibiarkan begitu saja dari dimensi pengembangan model-model pembelajaran bahasa Indonesia untuk penutur asing. Upaya-upaya menyiapkan model—model pembelajaran BIPA yang tepat telah banyak dilakukan. Penyediaan sumber-sumber belajar BIPA juga sudah banyak dilakukan baik oleh pemerintah maupun lembaga-lembaga bahasa di sejumlah kampus. Pelibatan sejumlah tenaga dosen sebagai instruktur BIPA di kedutaan-kedutaan Indonesia di berbagai negara juga menunjukkan betapa bahasa dan budaya Indonesia semakin dirasakan penting untuk diketahui dan dipahami [5].

Makalah ini hanya berfokus pada salah satu dari upaya-upaya yang disebutkan di atas itu, yakni memaparkan bagaimana konteks intralinguistik dan konteks ekstralinguistik sangat penting dipahami oleh para pembelajar BIPA. Dengan demikian masalah yang diangkat dalam penelitian ini adalah aspek-aspek konteks intralinguistik dan konteks ekstralinguistik apa saja yang harus dipahami oleh para pembelajar BIPA agar mereka memiliki kompetensi komunikatif berbahasa Indonesia yang benar-benar baik [6].

Konteks secara garis besar dapat dibedakan menjadi dua, yakni konteks linguistik atau yang lazim disebut koteks, dan konteks ekstralinguistik atau yang lazim disebut dengan istilah konteks saja. Konteks linguistik dapat diperinci ke dalam aspek yang sifatnya segmental dan aspek yang sifatnya suprasegmental. Adapun konteks ekstralinguistik dapat diperinci ke dalam konteks yang bersifat sosial, sosietal, kultural, dan situasional [7], [8]. Dalam lingkup kultur Jawa, misalnya saja, dimensi-dimensi nonverbal juga sangat kuat berpengaruh terhadap makna pragmatik atau maksud. Dimendi-dimensi nonverbal itu dapat bersifat paralinguistik, baik paralinguistik yang bersifat kinesik maupun paralinguistik yang bersifat pasimologis. Setiap elemen konteks dan aspek-aspek yang bertali-temali akan dideskripsikan secara terperinci pada bagian berikut ini.

\section{METODE}

Penelitian ini bertujuan memaparkan konteks intralinguistik dan konteks ekstralinguistik yang harus diperhitungkan dan dipertimbangkan dalam memaknai maksud penutur, khususnya bagi para penutur asing yang sedang belajar bahasa Indonesia (BIPA). Data penelitian ini dikumpulkan dari berbagai sumber referensi dan sejumlah pakar sebagai otoritas. Selain itu data penelitian ini juga dibangkitkan dari intuisi kebahasaan peneliti mengingat bahwa peneliti adalah penutur asli bahasa Indonesia. Metode pengumpulan data yang digunakan dalam penelitian ini adalah metode simak dan metode cakap, semuanya diterapkan dengan teknik dasar dan teknik lanjutannya [9]. Selanjutnya, data yang telah terkumpul diklasifikasi dan ditipifikasi untuk mendapatkan tipe-tipe data untuk dikenai metode dan teknik analisis yang tepat. Metode analisis yang digunakan dalam penelitian ini adalah metode metode analisis isi. engan menerapkan metode analisis ini, peneliti dimungkinkan untuk mengintepretasi fenomena-fenemona bahasa dalam interaksi sosial yang sesungguhnya. Hasil analisis disajikan dengan metode informal. Adapun yang dimaksud dengan metode penyajian informal ini adalah bahwa sajian dilakukan dengan kata-kata biasa, bukan dengan sajian yang berupa rumus-rumus yang menggunakan simbol [10].

\section{HASIL DAN PEMBAHASAN}

Dari penelitian yang telah dilakukan, aspek-aspek konteks intralinguisitk yang perlu diperhatikan oleh para pembelajar BIPA dipaparkan atu persatu sebagai berikut. 
Pertama, ihwal makna denotasi dan makna konotasi. Pada awal mulanya, di dalam studi makna secara semantis, konteks intralinguistik tidak juga perlu diperhitungkan Bahkan bisa disebut pula bahwa makna linguistik atau makna semantik itu adalah makna yang sifatnya denotasional, bukan makna yang sifatnya konotatif. Makna donotatif atau makna denotasional adalah makna yang melekat pada entitas bahasa tertentu tanpa terpengaruh konteks yang melingkupinya. Oleh karena itu, makna donotasional juga disebut makna konseptual [11], [12]. Pembelajar BIPA semestinya memahami dengan baik fakta kebahasan ini.

Kedua, ihwal entitas kebahasaan yang mendahului dan yang mengikuti. dalam kaitan dengan makna semantik yang lebih baru, konteks intralinguistik kiranya menjadi semakin penting untuk dilibatkan dan diperbincangkan. Deiksis persona 'dia' atau yang termanifestasi dalam klitika '-nya', misalnya saja, tidak dapat dilepaskan dari entitas kebahasan yang mendahuluinya, misalnya saja karena pada awalnya telah disebut nama seseorang. Jadi jelas, bahwa konteks intralinguistik itu bertali-temali dengan entitas kebahasaan yang mengawali atau pun yang mengikuti baik secara langsung dalam kalimat yang sama, atau mungkin pada kalimat lain jika merupakan sebuah wacana [13], [4].

Ketiga, ihwal tinggi-rendah bunyi tuturan. Aspek-aspek intrakebahasan yang berpengaruh terhadap pemaknaan itu di antaranya adalah masalah tinggi-rendahnya bunyi ketika mengujarkan sesuatu. Ketika aspek-aspek segmental dibunyikan, dimensi-dimensi suprasegmental terkait tinggi-tendah ini selalu dilibatkan. Tinggi rendah pengucapan mencakup tiga hal, yakni nada, toda, dan pitch. Nada dapat dipilah menjadi dua, yakni nada turun dan nada naik. Nada turun digunakan oleh menutur untuk menandai kelengkapan tuturan, sedangkan nada naik lazimnya digunakan untuk menandai ketidaklangkapan tuturan [14]. Dalam pragmatik variasi-variasi nada demikian itu sangat berpengaruh dalam penentuan makna kalau entitasnya berupa kata, atau maksud kalau entitasnya berupa kalimat. Hal demikian tidak dapat diabaikan oleh para pembelajar BIPA karena akan sangat berpengaruh di dalam berkomunikasi.

Keempat, variasi-variasi nada. Variasi-variasi nada yang terdapat dalam kalimat lazimnya disebut intonasi. Intonasi tuturan dapat bersifat datar-turun, datar-naik, dan datar-tinggi. Intonasi datar-turun lazimnya ditemukan dalam kalimat-kalimat berita. Intonasi datar-naik biasa digunakan untuk menyampaikan kalimat tanya. Adapun intonasi yang bersifat datartinggi lazimnya digunakan untuk menyatakan perintah. Variasi nada yang digunakan oleh penutur dan mitra tutur harus menjadi bahan pertimbangan pokok untuk mengetahu maksud tuturan dan maksud penutur. Variasi nada, baik yang berupa tona maupun yang berupa intonasi, dapat pula digunakan untuk menunjukkan maksud-maksud yang sifatnya emotif [15], [16].

Konteks intralinguistik sangat bertali-temali dengan persoalan keras-lemahnya bunyi ini. [17]Tekanan dapat bervariasi menjadi 4, yakni tekanan lemah, tekanan sedang, tekanan keras, dan tidak ada tekanan. Dalam bahasa Indonesia variasi tekanan keras-lemah seperti yang disebutkan di atas itu tidak mengubak makna, tetpai dapat mengubah maksud. Maksudmaksud penonjolan maksud lazimnya dituangkan dalam bentuk keras-lemah. Jika tekanan itu terjadi pada tataran kata disebut dengan tekanan yang bersifat silabis, sedangkan apabila terjadi pada tataran kalimat tekanan itu dikatakan bersifat leksis. Pembelajaran BIPA tentu saja tidak dapat mengesampingkan fakta kebahasaan ini.

Kelima, ihwal panjang-pendek bunyi tuturan. Aspek suprasegmental selanjutnya yang sangat penting untuk diperhatikan adalah persoalan panjang-pendeknya bunyi tuturan. Durasi dalam mengucapkan kata tertentu, atau mungkin durasi dalam mengungkapkan kaliat tertentu, sangat berpengaruh pada maksud tuturan, bukan pada makna secara semantis. Secara fonemis pun persoalan durasi bukanlah penentu makna. Selanjutnya aspek suprasegmental yang juga 
sangat penting untuk dibicarakan dalama rangka perbincangan konteks intralinguistik adalah masalah kesenyapan. Kesenyapan dapat dibedakan menjadi dua, yakni jeda dan sendi atau juncture [18]. Pembelajara BIPA, khususnya warga asing, harus sangat pemperhatikan kenyataan kebahasaan ini.

Keenam, ihwal kolokasi kata. Selain aspek-aspek segmental dan suprasegmental seperti yang dipaparkan di atas, ternyata persoalan lingkungan kebahasaan juga bertali-temali dengan kolokasi kata dalam kalimat. Adapun yang dimaksud dengan kolokasi kata adalah kesanggupan sebuah kata untuk bersanding dengan kata yang lainnya dalam sebuah kalimat. Lingkungan fisik kebahasaan tidak lepas dari persoalan ini, selain juga bersentuhan dengan masalah-masalah terkait dengan entitas kebahasaan baik yang mendahului maupun yang mengikutinya [19]. Dalam penyusunan bahan ajar BIPA, fakta kebahasaan yang demikian ini harus senantiasa dipertimbangkan dan diperhitungkan.

Dalam pencermatan peneliti selama ini, konteks ekstralinguisitk itu dapat dibedakan menjadi empat, yakni konteks sosial, konteks sosietal, konteks kultural, dan konteks situasional. Nah, pada bagian berikut ini setiap jenis konteks ekstralinguistik tersebut dipaparkan secara terperinci.

Pertama, konteks sosial atau konteks yang bersifat kemasyarakatan selama ini banyak dimanfaatkan dalam studi sosiolinguistik dan sosiopragmatik. Fokus studi sosiolinguistik terletak pada varian-varian bahasa karena sosiolinguistik mau menunjukkan bahwa bahasa itu tidak bersifat homogen sebagaimana telah kuat sekali dicanangkan oleh kaum formalistik dalam studi linguistik. Pemisahan entitas bahasa dari dimensi sosial atau pemisahan bahasa dari dimensi kemasyarakatan adalah sebuah kemustahilan karena pada hakikatnya bahasa adalah cermin sosial [20]. Dengan demikian dapat dikatakan bahwa bahasa itu menunjukkan bangsanya, 'language is a social mirror' [21]. Konteks sosial yang demikian ini tidak mungkin diabaikan oleh para pembalajar BIPA agar komunikasi dengan bahasa Indonesia berjalan dengan optimal.

Kedua, konteks sosietal. Jacob L. Mey berpendapat bahwa konteks yang bersifat sosietal demikian itu bersifat sosial vertikal, bukan sosial horizontal. Hubungan sosial yang bersifat vertikal demikian itu lekat dengan yang disebut sebagai status sosial [22]. Dengan perkataan lain, relasi vertikal masyarakat itu bertali-temali dengan status sosial. Jika seorang pembantu rumah tangga berbicara denga tuan rumahnya, yang kebetulan sekali adalah seorang priyayi, maka kentara sekali di situ terdapat dimensi yang bersifat sosial vertikal. Para pembelajar BIPA tentu saja tidak dapat mengabaikan kenyataan kebahasaan ini demi lancarnya komunukasi dan interaksi dengan bahasa Indonesia.

Ketiga, konteks kultural. Konteks sosial dan konteks sosietal tidak dapat dilepaskan dari konteks kultural. Dimensi etika dalam budaya mengharuskan seseorang untuk mengetahui sejauh mana nilai-nilai budaya harus dihargai dan dihormati dalam kehidupan bersama, dalam komunitas hidup bersama [23], [24]. Nilai sopan santun yang sekarang sudah banyak luntur karena tidak lagi dikuasai oleh banyak warga masyarakat, sedapat mungkin harus ditumbuhkan kembali, harus dihidupkan kembali, karena sopan-santun sesungguhnya adalah salah satu manifestasi dari etika dalam budaya. Nilai-nilai estetika yang sekarang juga sudah banyak tidak diperhatikan oleh seseorang dalam berbusana, misalnya saja, ketika berangkat beribadah ke gereja, seseorang berpakaian yang sangat tidak mengabaikan estetika. Konteks kultural mutlak dipahami oleh para pembelajar BIPA karena sesungguhnya bahasa tidak pernah dapat lepas dari aspek konteks kultural seperti disebutkan di depan itu.

Keempat, konteks situasional. Apa sajakah aspek-aspek konteks situasi yang membentuk konteks pragmatik? (1) Penyapa dan Pesapa. Dimensi-dimensi yang berkaitan dengan diri 'penyapa' dan 'pesapa', yang juga dapat disebut sebagai 'penutur' dan 'mitra tutur', atau 
'utterer' dan 'interpreter', atau 'speaker' dan 'hearer', ternyata dapat bermacam-macam, misalnya saja umurnya, jenis kelaminnya, latar belakang pendidikannya, latar belakang ekonominya, latar belakang sosial dan budayanya, latar belakang etnisnya, dan masih banyak lagi latar-latar yang lainnya. (2) Konteks tuturan. Konteks tuturan mencakup dimensi-dimensi linguistik atau yang sifatnya tekstual (textual context) atau yang sering pula disebut sebagai 'cotext', konteks yang sifatnya sosial-kultural (sociocultural context), dan konteks pragmatik (pragmatic context). (3) Tujuan tuturan. Perlu ditegaskan bahwa 'tujuan' atau 'fungsi' tuturan itu lebih tepat digunakan untuk menggantikan istilah 'maksud tuturan' atau mungkin, istilah 'maksud penutur' menyapaikan tuturan tertentu. (4) Tuturan sebagai bentuk tindakan. Gramatika tidak berurusan dengan tindak-tindak verbal itu karena yang menjadi titik fokus dalam gramatika itu adalah unsur-unsur kebahasaan, bukan tindak-tindak verbal. (5) Tuturan sebagai produk tindak verbal. Kalau di bagian terdahulu sudah dengan jelas dikatakan bahwa tuturan atau ujaran itu merupakan tindak-tindak verbal (verbal acts), ternyata dalam tataran yang lain juga harus dikatakan bahwa tuturan itu merupakan produk dari tindak verbal itu sendiri. Konteks situasi sebagai penentu maksud dalam bertutur sapa dalam sebuah bahasa, hendaknya menjadi perhatian yang sungguh signifikan bagi para pembelajara BIPA. Melepaskan konteks situasi seperti yang dipaparkan di bagian depan, sama saja berarti tidak berhasilkan komunikasi dan interaksi dalam bahasa itu.

\section{SIMPULAN}

Sebagai penutup dapat disampaikan bahwa penelitian ini telah menemukan aspek-aspek konteks intralinguistik dan konteks ekstralinguistik yang sangat perlu dipahami oleh warga asing sebagai pembelajar BIPA. Aspek-aspek konteks intralinguistik mencakup Pertama, ihwal makna denotasi dan makna konotasi; Kedua, ihwal entitas kebahasaan yang mendahului dan yang mengikuti; Ketiga, ihwal tinggi-rendah bunyi tuturan; Keempat, variasi-variasi nada; Kelima, ihwal panjang-pendek bunyi tuturan; Keenam, ihwal kolokasi kata; Adapun aspekaspek konteks ekstralinguistik yang perlu dipahami pembelajar BIPA mencakup: Pertama, konteks sosial atau konteks yang bersifat kemasyarakatan selama ini banyak dimanfaatkan dalam studi sosiolinguistik dan sosiopragmatik; Kedua, konteks sosietal; Ketiga, konteks kultural; Keempat, konteks situasional. Pemahaman aspek-aspek dari kedua jenis konteks tersebut sangat penting untuk membantu para pembelajara BIPA benar-benar memiliki kemampuan berkomunikasi dalam bahasa Indonesia secara optimal.

\section{REFERENCES}

[1] H. Susanto, "Membangun Budaya Literasi Dalam Pembelajaran Bahasa Indonesia Menghadapi Era MEA,” JP-BSI (Jurnal Pendidik. Bhs. dan Sastra Indones., 2016.

[2] R. K. Rahardi, Y. Setyaningsih, "Contextualizing Local Values of Children's Games in the Perspective of Ecopragmatics to Enhance Culture-Specific Based Communication," Int. J. Eng. Adv. Technol., vol. 9, no. Issue-1, October 2019, pp. 143-151, 2019.

[3] M. Marsudi, S. Zahrok, and U. Arief, "Kesadaran Pemakai Bahasa Indonesia Di Era Teknologi," J. Sos. Hum., 2013.

[4] R. K. Rahardi, "Pragmatic Perspective on Phatic Functions and Language Dignity," Int. J. Eng. Adv. Technol., vol. 8, no. 5C, May 2019, pp. 261-268, 2019.

[5] I. Suyitno, "Pengembangan Bahan Ajar Bahasa Indonesia untuk Penutur Asing (BIPA) berdasarkan Hasil Analisis Kebutuhan Belajar," Wacana, J. Humanit. Indones., 2007. 
[6] I. Santoso, "Pendidikan Karakter Dan Pembelajaran Bahasa Asing Berwawasan Interkultural," J. Pendidik. Karakter, 2012.

[7] R. K. Rahardi, "Elemen dan Fungsi Konteks Sosial, Sosietal, dan Situasional dalam Menentukan Makna Pragmatik Kefatisan Berbahasa," in Prosiding Seminar Tahunan Linguistik Universitas Pendidikan Indonesia (SETALI 2018), 2018, pp. 654-658.

[8] Y. Setyaningsih and R. K. Rahardi, "Quality Of Arguments Used In The First-Round Presidential Debate: Critical Pragmatics And Stephen Toulmin's Perspective," Int. J. Eng. Adv. Technol., vol. 8, no. 5C, pp. 716-725, 2019.

[9] M. Mahsun, "Metode Penelitian Bahasa," Jakarta PT Raja Grafindo Persada, 2005.

[10] Sudaryanto, Metode dan Aneka Teknik Analisis Bahasa: Pengantar Penelitian Wahana Kebudayaan secara Linguistis, 1st ed. Yogyakarta: Sanata Dharma University Press, 2015.

[11] A. LASCARIDES and A. COPESTAKE, "Pragmatics and word meaning," $J$. Linguist., 1998.

[12] D. Carbaugh and B. van Over, "Interpersonal pragmatics and cultural discourse," Journal of Pragmatics. 2013.

[13] E. Ifantidou, "The semantics and pragmatics of metadiscourse," J. Pragmat., 2005.

[14] J. House, "Constructing a context with intonation," J. Pragmat., 2006.

[15] C. Caffi and R. W. Janney, "Toward a pragmatics of emotive communication," J. Pragmat., 1994.

[16] M. Ephratt, “The functions of silence," J. Pragmat., 2008.

[17] D. E. Hinton and M. La Roche, "Cultural Context," in The Wiley Handbook of Cognitive Behavioral Therapy, 2013.

[18] I. McGee, "The pragmatics of paragraphing English argumentative text," J. Pragmat., 2014.

[19] S. P. Wang, "Corpus-based approaches and discourse analysis in relation to reduplication and repetition," Journal of Pragmatics. 2005.

[20] P. Eckert, "Variation and the indexical field," Journal of Sociolinguistics. 2008.

[21] R. K. Rahardi, "Personal and Communal Assumptions to Determine Pragmatic Meanings of Phatic Functions," Ling. Cult., vol. 10, no. 10(2), pp. 95-98, 2016.

[22] L. R. Waugh, T. Catalano, K. Al Masaeed, T. H. Do, and P. G. Renigar, "Critical discourse analysis: Definition, approaches, relation to pragmatics, critique, and trends," in Perspectives in Pragmatics, Philosophy and Psychology, 2016.

[23] I. Context, "Ict in Cultural and Social Context," Commun. ACM, 2006.

[24] D. Ben-Amos, "Context' in Context," West. Folk., 2011. 